\title{
The Study on Dilemma and Solution of Teaching Reformation of Medical Physics in Local Medical University
}

\author{
Benchao Zhu ${ }^{1, a}$, Weiwei Jiang ${ }^{2, b}$ and Fan Zhang ${ }^{2, c}$ \\ ${ }^{1}$ Hubei University of Medicine, Mathematics and Physics Department, Shiyan 442000, China \\ ${ }^{2}$ Hubei Dongfeng Automobile Technician College, Shiyan 442000, China \\ azbc8@hbmu.edu.cn, bjww0507@163.comn, ${ }^{\mathrm{c}} 326386321 @ q q . c o m$
}

Keywords: The university transformation; Medical physics; Teaching reformation; Dilemma

\begin{abstract}
Faced with the policy of the encouragement local university transformation to skill and applied type from Ministry of Education, the public courses are in the position to carry on a new round of teaching reform. After presented the present situation and usually reformation forms of medical physics course in the local medical universities, a common phenomenon, simple reducing teaching hours of medical physics, is discussed detailed in the teaching reform of local medical colleges. Then, the paper demonstrates this lack of respect for the teaching reform of science, and ultimately makes the teaching of medical physics trapped in local medical universities, the plight of teaching management, teachers and students to the many puzzles. Based on the principles of pedagogy, it is proved that this kind of teaching reform will eventually reduce the teaching quality of local medical colleges and universities. Finally, this article through the author in recent years some teaching experience, to provide some solutions to this kind of teaching reform predicament, hope these measures can cause the attention of colleagues.
\end{abstract}

\section{论当下地方医学院校《医学物理学》课程教学改革 的困境及解决方法}

\author{
朱本超 ${ }^{1, \mathrm{a}}$, 蒋薇薇 ${ }^{2, \mathrm{~b}}$, 张钒 ${ }^{2, \mathrm{c}}$ \\ 1. 湖北医药学院, 数理教研室, 中国 湖北十堰 442000 \\ 2. 湖北东风汽车技师学院, 中国 湖北十堰 442000 \\ azbc@hbmu.edu.cn, bjww0507@163.com, 326386321@qq.com
}

摘要: 面对国家在 2014 年初提出鼓励地方高校转型技能型、应用型机遇, 地方医学院校的 公共基础课面临新一轮的教学改革。通过对当下地方医学院校的《医学物理学》课程现状, 分析一些地方医学院校《医学物理学》课程的教学改革的主要表现形式, 探讨了《医学物 理学》课程在地方医学院校教学改革中出现的一种常见现象, 即单纯地减少教学学时, 而 缺少科学地配套其它课外教学改革和一些相关学科联动教学改革调研等措施, 论证了这种 不尊重科学的教学改革, 最终使得《医学物理学》课程的教学在地方医学院校陷入了困境, 这种困境给教学管理者、教师和学生都来了许多困惑。以教育学原理出发, 论证了这种教 学改革最终会降低地方医学院校物理学课程教学质量。最后, 本文通过笔者近些年的一些 教学经历, 对这种教学改革困境提供一些解决方法, 希望这些措施能够引起同仁们的注意。

关键词: 高校转型; 医学物理学; 教学改革; 困境

\section{1. 引言}

2014 年，教育部把高等教育结构调整作为 “十三五” 高等教育改革的主要任务, 突破口就是 地方本科院校转型发展 $[1,2]$ 。作为五年制临床专业为主的地方医学院校, 对于此种应用转型 
尤为欢迎。面对新政策, 地方医学院校对各科课程开始了新一轮的教学改革热潮, 其中尤以 基础类公共课程改革力度最大, 引起的思考较多。本文将以医学院各类专业的公共基础课,

《医学物理学》在这种政策作用下的改革为研究对象, 论述该课程教学改革陷入的困境及解 决的方法。

\section{2. 地方医学院校《医学物理学》课程开设现状}

目前, 我国地方医学院校中, 《医学物理学》作为各医学专业学生必修公共基础课进行开设。 《医学物理学》课程教学分为理论教学和实验教学, 理论教学和实验教学内容可总结为下表 $[3,4]$ :

\section{表 1 医学院校《医学物理学》课程理论教学与实验教学内容}

\begin{tabular}{|c|c|c|c|c|c|}
\hline & 理论教学内容 & 实验教学内容 & & $\begin{array}{l}\text { 理论教学内 } \\
\text { 容 }\end{array}$ & $\begin{array}{l}\text { 实验教学内 } \\
\text { 容 }\end{array}$ \\
\hline & $\begin{array}{l}\text { 牛顿力学 (物 } \\
\text { 体的弹性等) }\end{array}$ & $\begin{array}{l}\text { 力学: 转动惯量测 } \\
\text { 量、人造骨杨氏模量 } \\
\text { 测量等 }\end{array}$ & & $X$ 射线物理 & $\begin{array}{l}X \text { 射线影像 } \\
\text { 原理、CT 成 } \\
\text { 像实验 }\end{array}$ \\
\hline & $\begin{array}{c}\text { 流体运动规律 } \\
\text { (人体血液、 } \\
\text { 呼吸循环系统 } \\
\text { 的物理规律) }\end{array}$ & $\begin{array}{l}\text { 流体: 液体粘滞系数 } \\
\text { 测量, 伯努利方程验 } \\
\text { 证等 }\end{array}$ & & $\begin{array}{l}\text { 激光的医学 } \\
\text { 应用 } \\
\text { 红外线物理 }\end{array}$ & $\begin{array}{l}\text { 红外线成像 } \\
\text { 实验 }\end{array}$ \\
\hline $\begin{array}{l}\text { 经 } \\
\text { 典 } \\
\text { 物 }\end{array}$ & $\begin{array}{l}\text { 声波学（超声 } \\
\text { 波的医学应 } \\
\text { 用） }\end{array}$ & $\begin{array}{l}\text { 声波: } \mathrm{A} 、 \mathrm{~B} \text { 超声波 } \\
\text { 原理, 人耳听痛觉曲 } \\
\text { 线测量等 }\end{array}$ & $\begin{array}{l}\text { 近 } \\
\text { 代 } \\
\text { 物 }\end{array}$ & MRI 物理 & $\begin{array}{l}\text { 核磁共振实 } \\
\text { 验 }\end{array}$ \\
\hline 理 & $\begin{array}{l}\text { 热力学及分子 } \\
\text { 动理论（热学 } \\
\text { 及气体栓塞的 } \\
\text { 物理规律） }\end{array}$ & $\begin{array}{l}\text { 分子动理论: 表面张 } \\
\text { 力系数测量, 气体栓 } \\
\text { 塞验证等 }\end{array}$ & 理 & 核医学概论 & $\begin{array}{l}\text { 放射性活动 } \\
\text { 测量实验 }\end{array}$ \\
\hline & $\begin{array}{l}\text { 波动和几何光 } \\
\text { 学 }\end{array}$ & $\begin{array}{l}\text { 光学: 显微镜放大 } \\
\text { 率、非正式眼矫正、 } \\
\text { 全息照相等 }\end{array}$ & & $\begin{array}{l}\text { 相对论物理 } \\
\text { 概论 }\end{array}$ & 无相关实验 \\
\hline & $\begin{array}{l}\text { 医学相关的电 } \\
\text { 磁学理论（含 } \\
\text { 基本电路） }\end{array}$ & $\begin{array}{l}\text { 电磁学: 心电图机技 } \\
\text { 术指标、各类传感器 } \\
\text { 实验 }\end{array}$ & & $\begin{array}{l}\text { 量子物理概 } \\
\text { 论 }\end{array}$ & 无相关实验 \\
\hline
\end{tabular}

上表是医学物理学课程能够涵盖的理论及实验教学的所有部分。在不同性质的医学院校, 课 程开设具有较大差异。以地方医学院校为例, 笔者总结了当下地方医学院校《医学物理学》 课程开设现状：第一，课程定位于 “素质教育” 课程, 课程开设学时较一般理工科少。第二, 课程教科研支撑不足。第三, 课程授课对象质量降低。第四, 课程突出点不够, 被学生抱怨 现状持续。第五，课程教师师资不足，教师疲于教学，教学亮点不多 [5]。

\section{3. 地方医学院校《医学物理学》教学改革的现状及困境}

面对地方医学院校《医学物理学》课程开设现状的困惑, 地方医学院校对公共类课程的教学 改革从未停止过。如今在国务院在 “十二五” 规划后期提出以培养学生就业能力为导向的教 育改革布局, 鼓励地方高校转型前提下, 地方医学院校势必又会对诸如《医学物理学》等公 
共基础课的改革提上日程。地方医学院校对《医学物理学》课程的教学改革思路, 可以通过 笔者所在学校近八年的对临床等专业教学任务图标呈现出来:

\section{图 12007 -2015 湖北医药学院《医学物理学》课程教学改革表现}

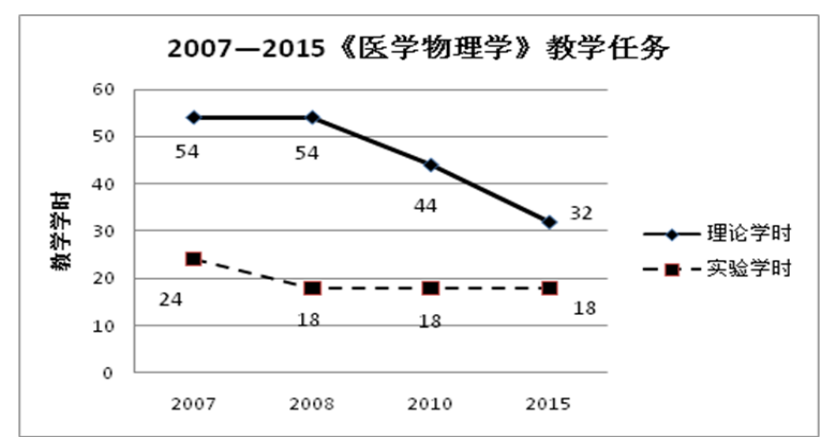

通过上图可以清晰看到, 在九年时间内, 我校 (湖北十堰, 湖北医药学院) 对《医学物理学》 课程进行了四次教学改革。注意, 这些教学改革虽然形式上先将教务处意见稿发于教研室进 行讨论, 但是, 教务处每次都有已经成型的教学改革模板。这种下发任务式的教学改革, 缺 少了科学性地调研而多了一些家长制作风, 但是从内容及功能上来讲, 地方医学院校这样的 教学改革具有以下几个特点: 第一, 课程教改形式单一, 几乎就是 “减少教学学时”。在缺少 类似于国家下发的保证高校思政课教学学时的政策 [6], 使得地方医学院校对基础公共课教改 就是减少教学时。第二, 课程教改配套不足, 在减少了教学学时后, 地方医学院校并未给出 相应地配套改革。第三, 课程教改的整体联动考虑不够, 地方医学院校进行物理学课程教改 过程中, 往往缺乏对自然科学课程的联动性认识。孤立地将物理学课程进行教学改革, 而没 有将物理学同高等数学、生物学甚至化学等课程进行全盘考虑。第四, 课程教改缺乏科学严 谨性。地方医学院校对《医学物理学》课程进行教改时, 往往对物理学的认识缺乏科学性, 对自然科学内容的严谨性缺乏足够的了解。以上小结的地方医学院校对《医学物理学》课程 教学改革的现状, 决定了该课程在地方医学院校陷入了困境。虽然是自然科学的公共基础课 程, 但是教学管理时理论教学学时任意变动、教学投入时实验教学条件无法与时俱进, 同时 又要求物理教师将物理学教学服务于医学专业, 这些因素造成了地方医学院校的物理教师教 学的困惑, 地方医学生不知物理所学何用等困境。

\section{4. 地方医学院校《医学物理学》教学改革困境的解决方法}

如何解决地方医学院校《医学物理学》课程教学改革的困境, 是每位从业人员都在思考并希 望解决的问题。以笔者近十年的教学经历来看, 解决地方医学院校公共类基础课程的教学改 革困境的问题, 确实是一个牵扯了许多环节 $[8,9,10]$, 归纳而言, 包括以下四个方面:

(1) 《医学物理学》教学改革政策应具有民主性、科学性。教学改革有广义和狭义之分, 广义 上讲, 教学改革包括各层面教育制度的改革, 也即各层面教育政策的改革 [8]。作为地方医学 院校教务管理部门, 制定教学改革政策时, 不应该家长制下发教改任务。更不应该在相关学 科教师 (一线教师) 缺席情况下制定教学改革相关政策。物理学科的特有结构及内容的完整 性、科学性等特点, 都是教学改革政策制定过程中必须考虑的。地方医学院校的教务人员, 往往不具备考虑这些问题的学科背景, 只是制定减少教学学时的政策, 从源头上对教学改革 增加了阻碍, 这种现状的解决方法就是要耐心的调研、民主地放权, 尊重学科科学性。

(2)《医学物理学》教学改革要注意教改的结构, 地方医学院校教学改革过程中以减少教学学 时的理由各不相同, 但是对于物理学教学改革结构调整并不重视。减少教学学时自然是一种 教学改革, 但是教学改革结构是整个学科教学实施的重要基础, 地方医学院校很注重一些先 进教学理念, 特别是应用于医学教学的 PBL、CBL 以及现在的自主性教学理念、慕课 (MOOC)、 
微课堂、翻转课堂等。这些教学理念就是一种教学改革结构搭建问题, 如果采用了其中一些 教学方法, 物理学教学的课堂教学学时确实应该减少, 但前提是相关配套改革已经同步。地 方医学院校在对待公共类基础课程教学改革时, 并未真正将教改结构搭建完毕后进行教改实 施，这就造成了在物理学科在减少教学学时后，没有后续配套的改革。

(3)《医学物理学》教学改革要注意同其它相关科目的联动教改, 地方医学院校由于自身特色, 对公共基础类课程认识限于医学及相关领域, 对自然科学中的物理、数学、化学和生物学之 间的关联理解不够。这种对相关科目联动认识的不足造成了制定教学改革时并未有全盘考虑。

《医学物理学》同化学中的热力学重复度很高, 物理学同生物学中关于生物力学、细胞膜内 外能量输运、生物电路等知识也有部分重复。很多时候减少物理学教学学时的同时, 要注意 其它相关科目联动调研, 组织相关学科教师进行内容上的接洽。但是地方医学院校对物理学 的教学改革仅仅只针对物理学。这种人为将自然科学进行分立的做法, 使得教学改革的效果 不可能达到最佳。

(4)《医学物理学》教学改革要注意一线教师的相关能力培训, 地方医学院校的物理学教师, 由于学历、工作环境、进修机会、学校提供的教科研资源等限制, 教师相关教科研能力很多 时候是跟不上学校相关教学改革政策的。近些年, 虽然地方医学院校财政有所改善, 但是公 共类基础课程教师的进修、培训还是稍显不足 [10]。在地方医学院校, 教务管理部门希望各 类公共课程与医学紧密结合, 但是只依靠物理教师自学的前提下, 其效果往往比较差。并且, 对一些年纪稍大的物理教师, 这种自学的动力和能力都不足, 这些现状的解决就要求地方医 学院校必须注意教学改革过程中教师的能力培训等问题。

\section{5. 结论}

以上就是本文对于当下地方医学院校对待公共类基础课程之一《医学物理学》教学改革过程 出现的普遍问题以及相关解决方法的探讨。相关从业人员必须重视地是, 在国家鼓励地方院 校转型之际, 地方医学院校的公共类基础课程必然会面对着一次重要教学改革。在此之前, 回顾并总结地方医学院校课程教学改革过程出现的这些问题, 对制定后续教学改革有着借鉴 作用。

\section{参考文献}

[1] 董洪亮, 地方本科高校该转型了（教育视界・聚焦部分本科院校转型（上））[N], 人民 日报，2014年5月8日，第18版：文教周刊.

[2] 董洪亮, 地方本科院校怎样转型（教育视界・聚焦部分本科院校转型（下）） [N], 人民 日报，2014年5月8日，第18版: 文教周刊.

[3] 王否, 医学物理学 (第8版) [M], 北京: 人民卫生出版社, 2013年版.

[4] 冀敏，医学物理学实验（第2版）[M]，北京：人民卫生出版社，2012年版.

[5] 颜红金, 医学物理学与医学课程相结合的研究 [J], 中国医学物理学杂志, 2014, 31 (1): 4718-4722.

[6] 教育部思想政治工作司网站相关政策, http://www.moe.edu.cn/s78/A12/

[7] 王晓艳;纪绪财; 王鹏程;谢晋东, 医学物理学特色专业建设的研究与思考 [J], 中国医学物 理学杂志, 2014, 31(4):5095-5100.

[8] 方立铭;李国柱;程桂平, 医学物理学课程教学改革的方向与创新[J], 当代教育论坛, 2010 年第4期:100-101.

[9] 喀蔚波, 医学物理学教育的现状与思考[J], 中国医学物理学杂志, 2002, 19(4): 198-200. 
[10] 孙素梅, 探索物理学与医学相结合的教学模式[J], 卫生职业教育, 2015(1):52-53.

\section{References}

[11] Dong HL. Right time to transformation of local undergraduate colleges (Education vision focusing on the transformation of undergraduate colleges (I)) [N], People's daily, May 8, 2014, eighteenth edition: Education weekly.

[12] Dong HL. How to transformation of local undergraduate colleges (Education vision - focusing on the transformation of undergraduate colleges (II))[N], People's daily, May 8, 2014, eighteenth edition: Education weekly.

[13] Wang L. Medicine Physics (Eighth Edition) [M], Bei Jing: People's Health Publishing company, 2013.

[14] Ji M. Medicine Physics Experiment (First Edition) [M], Bei Jing: People's Health Publishing company, 2009.

[15] Yan HJ. Research on the combination of medical physics and medical curriculum [J], Chinese Journal of Medical Education, 2014, 31(1): 4718-4722.

[16] Department of Ideological and political work of the Ministry of Education, http://www.moe.edu.cn/s78/A12/

[17] Wang XY, Ji XC, Wang PC, Xie JD, Research and Consideration on the construction of characteristic specialty in medical physics[J], Chinese Journal of Medical Education, 2014, 31(4):5095-5100.

[18]Fang LM, Li GZ, Cheng GP, The direction and innovation of Reformation of Medical Physics Teaching[J], Contemporary Education Forum, 2010, 4: 100-101.

[19] Ka WB, Present situation and thinking of Medical Physics Education [J], Chinese Journal of Medical Education, 2002, 19(4): 198-200.

[20] Sun SuMei, Exploring the teaching mode of physics and medicine [J], Health Vocational Education, 2015, 33(1):52-53.

作者简介: 朱本超 (1982 年一), 男, 湖北武汉, 副教授, 主要从事医学物理学教学, 医学 影像物理学教学研究, E-mail: zbc@hbmu. edu. cn 